\title{
Narrativas sobre \\ el conflicto armado y \\ la construcción de paz: \\ Arauca, entre el miedo \\ y la indignación*
}

\author{
Narratives \\ about Armed \\ Conflict and \\ Peacebuilding: \\ Arauca, between \\ Fear and \\ Indignation
}

Primer semestre de 2020 - pp. 183-197 Segunda época

N.
Narrativas sobre

o conflito armado

e a construção

da paz: Arauca,

entre medo e

indignação

\section{Keilyn Julieth Sánchez Espitia**}

Marieta Quintero Mejía*** Orcid: http://orcid.org/0000-0002-8001-4511

* El presente artículo de investigación científica se deriva de los resultados obtenidos en el Proyecto Voces y experiencias territoriales por una cultura de paz y reconciliación, avalado y financiado por Colciencias en la Convocatoria Jóvenes investigadores e innovadores por la Paz 2017, a través del Convenio 425 de 2017 y el Contrato 982-I de 2018.

** Licenciada en Educación Básica con énfasis en Humanidades y Lengua Castellana y Magíster en Educación de la Universidad Distrital Francisc José de Caldas. Joven investigadora Colciencias 2017. Miembro del Grupo de Investigación Moralia. Coordinadora del Programa Escuelas PazArte de la Fundación In-Ju Huellas. Miembro del Colectivo Educación Para La Paz.

Correo electrónico: kjsancheze@correo.udistrital.edu.co

*3 Doctora en Ciencias Sociales, Niñez y Juventud de la Universidad de Manizales -Cinde y Posdoctora en Ciencias Sociales, Niñez y Juventud de la Red de Posgrados Clacso. Coordinadora de la Maestría en Educación para la Paz y docente de planta de la Universidad Distrital Francisco José de Caldas. Codirectora del Grupo de Investigación Moralia. Directora Nacional del Colectivo Educa, Universidad Pedagógica Nacionalción para la Paz.

Correo electrónico: mquintero@udistrital.edu.co
Para citar este artículo

Sánchez, K., y Quintero, M. (2020). Narrativas sobre el conflicto armado y la construcción de paz: Arauca, entre el miedo y la indignación. Folios, 51, 183-197. doi: 10.17227/folios.51-9883<smiles>[CH]C=C</smiles>

Artículo recibido $22 \cdot 04 \cdot 2019$

Artículo aprobado $25-\bullet 07 \cdot 2019$ 


\title{
Resumen
}

El presente artículo de investigación tiene como propósito reconocer el papel que cumplen las emociones morales y políticas, específicamente el miedo y la indignación, presentes en narrativas de maestros y maestras del departamento de Arauca. Con énfasis en la comprensión del impacto del conflicto armado y los procesos de construcción de paz vividos en el territorio; comprensión que devela el lugar de la escuela como institución cooptada por la atrocidad, pero también, como uno de los escenarios garantes del postacuerdo. Para dar alcance a este objetivo, se explican los conceptos y atributos de las emociones analizadas. Posteriormente, se plantea el horizonte metodológico que orientó la realización del estudio, bajo un enfoque cualitativo y diseño narrativo. Finalmente, se sitúan los resultados de la investigación, vinculados con el miedo paralizador en medio del mal y la indignación frente al incumplimiento de los Acuerdos de Paz y la continuidad de la guerra en el departamento; indignación en la que los vestigios del amor se convierten en fuente de resistencia y movilización ante la nebulosidad de la crueldad humana.

\author{
Palabras clave \\ miedo; indignación; conflicto armado; construcción de paz
}

\begin{abstract}
The purpose of this article is to recognize the role played by moral and political emotions, specifically fear and indignation stated in the narratives of teachers from Arauca. Understanding the impact of armed conflict and peace construction process lived in the territory reveals the role of the school as a co-opted institution by atrocity, but also, as one of the guarantor scenario of the post-agreement. In order to achieve this objective, it will be explained some theoretical elements related with concepts and attributes of analyzed emotions. The methodological horizon that guided the study was presented, under a qualitative approach and narrative design. Finally, the result of investigation are stated, associated with paralyzing fear in the middle of war, the indignation in relation to peace agreement breach and the continuation of the conflict in the territory; indignation in which the vestiges of love become a source of resistance and mobilization before the nebulosity of human cruelty.

Key words

fear; indignation; armed conflict; peace construction
\end{abstract}

\section{Resumo}

0 objetivo deste artigo é reconhecer o papel desempenhado pelas emoções morais e políticas, especificamente 0 medo e indignação, que são expressas nas narrativas dos professores de Arauca, compreendendo o impacto do conflito armado e o processo de ;onstrução da pa; vivido no território; esse entendimento revela o papel da escola como instituição cooptada pela atrocidade, mas também como um dos cenários garantidores do pós-acordo. Para atingir este objetivo, serão explicados alguns elementos teóricos relacionados aos conceitos e atributos das emoções analisadas. Posteriormente, é apresentada a metodologia que orientou este estudo com uma abordagem qualitativa e desenho narrativo. Por fim, constata-se o resultado da investigação, associada ao medo paralisante no meio da guerra, à indignação ante a violação do acordo de paz e a continuação do conflito no território; indignação em que os vestígios do amor se tornam fonte de resistência e mobilização diante da nebulosidade da crueldade humana.

\section{Palavras-chave}

medo; indignação; conflito armado; construção da paz 


\section{Introducción}

La década de los noventa simbolizó el punto de ruptura para la marginación de narrativas y emociones como fuentes de comprensión del mal. El interés por documentar lo ocurrido en la Gran Guerra condujo al reconocimiento de cartas, diarios de combate, cuentos y novelas producidos por soldados británicos en medio de las confrontaciones, como corpus de análisis de lo acaecido; corpus que contenía un alto sustrato emocional (Carrera, 2015) No obstante, son los estudios póstumos a la Segunda Guerra Mundial, los encargados de reivindicar, a partir de las voces de víctimas, victimarios y testigos, las huellas emocionales de uno de los hitos más devastadores en la historia de la humanidad.

La experiencia del Totalitarismo, trajo consigo la aparición de trabajos acerca del orgullo nacionalista que cimentó la solución final, el miedo instaurado por las persecuciones y los procesos de segregación, la culpa de los sobrevivientes y el control emocional frente a los daños causados al pueblo judío, camuflado en los discursos progresistas que, finalizada la guerra, buscaron proyectar la mirada del pueblo alemán hacia el futuro, imposibilitando volver sobre las huellas del horror (Toro, 2015).

Estos trabajos dieron lugar a la producción cada vez más numerosa y especializada de literatura sobre el papel de las emociones en otros fenómenos atroces, tales como el franquismo (Romanos, 2011), el narcotráfico y terrorismo americano (Rodríguez, 2012) y las dictaduras militares en el Cono Sur (Cárdenas et ál., 2013; Toro, 2015) En otras palabras, la sensibilidad moral y política se posicionó como campo de indagación de los hechos de crueldad.

En el caso de Colombia, las investigaciones que buscan la comprensión de los efectos e impactos del conflicto armado a través de las emociones se sitúan a principios del siglo Xxi. Esta producción, se enfoca en develar las fibras emocionales presentes en las dinámicas y experiencias derivadas de este fenómeno de la guerra. Así, es posible referir estudios sobre el miedo y la vergüenza en el marco del reclutamiento (Guzmán Moreno et ál., 2016), las masacres (Bello, 2005) y el desplazamiento forzado
(Villa, 2006; Quintero, M., 2009); el dolor ante la ausencia de reparación de las víctimas (Salgado et ál., 2011); la culpa de sobrevivientes y victimarios (Bello, 2005; Franco, 2014).

Si bien las investigaciones que vinculan emociones y conflicto armado son de carácter reciente -atendiendo a las largas trayectorias de guerra acaecidas en el país-, lo son aún más aquellas que buscan analizar dicho vínculo en el escenario educativo. Autores como Lizarralde (2003; 2013), refiere la escuela como escenario cooptado por la guerra y permeado por el miedo, al ser convertido en campos de batalla. Otros como Quintero, (2015;2017), además de señalar estas afectaciones, refieren la importancia de promover una pedagogía de las emociones para convocar la comprensión de la historia de nuestro país y contribuir a la construcción de paz.

Aunado al estado naciente de los trabajos que buscan vincular estas tres coordenadas (emociones, conflicto armado y escuela), es preciso señalar la carencia de literatura encaminada a reconocer la experiencia sensible de maestros y maestras en el marco del conflicto armado y del actual proceso de posacuerdo. Dentro de los trabajos encontrados en este campo, se encuentran las investigaciones de Lizarralde $(2003 ; 2013)$, encaminadas a trazar las morfologías que adquiere el miedo en la experiencia docente en el marco de la atrocidad, como emoción que debilita los vínculos y acciones de los sujetos, pero también, se convierte en señal de alerta ante el peligro, generando formas de cuidado y protección. También, se ubican los estudios de Quintero (2015; 2017), los cuales buscan a través de las voces de maestros y maestras, reconocer las geopolíticas de las emociones que han marcado los hechos de guerra y construcción de paz, presentes en territorios como Huila, Caquetá y Chocó.

Tanto Lizarralde (2003; 2013), como Quintero(2015; 2017), han buscado reivindicar las narrativas de los docentes como víctimas invisibilizadas del conflicto armado. También, han promovido el reconocimiento y fortalecimiento de su capacidad de agencia para la construcción de paz. Sin embargo, los mismos autores coinciden en 
señalar que las iniciativas enfocadas en estos actores, son mínimas y tenues, razón por la cual requieren ser ampliadas y potenciadas; requerimientos que no se alejan de los desafíos definidos por el gobierno para el posacuerdo.

Dentro de las apuestas nacionales para el postconflicto, estipuladas en el Fondo Colombia en Paz -CONPES 3850-, se encuentra la promoción de una cultura de paz y reconciliación. Para dar alcance a este propósito, además de la finalización del conflicto armado se plantean, entre otros, la prevención y gestión de conflictos, la producción de relatos vinculados con la convivencia pacífica, así como el fortalecimiento de los centros educativos y las comunidades, como preventoras y promotoras de paz. De esta forma, el logro de la paz estable y duradera se encuentra ligado a la consolidación y fortalecimiento de las capacidades territoriales, para implementar proyectos e iniciativas que respondan a las necesidades específicas de las regiones y de la población local.

Aunado a lo anterior, con el ánimo de atender a los resultados arrojados por el Índice de Incidencia del Conflicto Armado desarrollado por el Departamento Nacional de Planeación (DNP)- entre 2002 y 2013, dichas apuestas nacionales resaltan la necesidad de focalizar la atención y los esfuerzos en las zonas rurales pertenecientes a las regiones más impactadas por este fenómeno de la atrocidad; impacto que ha tenido implicaciones de diversa índole, entre ellas, la erosión del tejido social, el desarraigo de las comunidades, la vulneración de derechos, la afectación del escenario educativo y la precarización de la calidad de vida de las comunidades.

Podemos señalar entonces, que las apuestas nacionales por el postconflicto no sólo implican asumir un enfoque que dé cuenta de los efectos particulares y diferenciales del conflicto armado en las regiones, sino también y especialmente, reconocer los saberes y aprendizajes territoriales en torno a la construcción de la cultura de paz y reconciliación. Así, las narrativas de los actores sociales acerca de la consecución de la paz sobrepasan la simple descripción de hechos o sucesos, pues contienen resistencias, luchas de reconocimiento, memorias colectivas y añoranzas de un futuro diferente. También, dan cuenta de iniciativas y experiencias - formalizadas o no-, orientadas a la resolución de conflictos y a la construcción de escenarios de convivencia pacífica en los territorios.

En el marco de lo anterior, este proyecto buscó reconocer el papel que cumplen las emociones morales y políticas, específicamente el miedo y la indignación, presentes en narrativas de maestros y maestras del departamento de Arauca, en la comprensión del impacto del conflicto armado y los procesos de construcción de paz vividos en este territorio, referido como uno de los más impactados por la guerra según el Îndice de Incidencia del Conflicto Armado (DNP, 2015)

\section{Marco teórico}

Los primeros autores en preguntarse ¿Qué es una emoción? Fueron Cheshire Calhoun y Robert Solomon, finalizada la década de los noventa. En su obra, la cual conserva este mismo nombre, los docentes refieren la pregunta por la sensibilidad humana, desde la Grecia Antigua, hasta nuestros días, manifestando de manera expresa que, si bien, el estudio de este campo de conocimiento no es propio de ninguna disciplina, su abordaje y desarrollo ha estado situado de manera especial en la psicología, el psicoanálisis y la filosofía (1996). Dicha trayectoria permite a los teóricos reconocer cinco enfoques desde los cuales han sido analizadas las emociones:

Tabla 1. Enfoques del estudio de las emociones

\begin{tabular}{|c|c|c|}
\hline Enfoque & Descripción & Exponente (s) \\
\hline 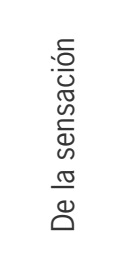 & $\begin{array}{l}\text { Asume la emoción } \\
\text { desde una perspectiva } \\
\text { psicológica, buscando } \\
\text { dar cuenta de la forma en } \\
\text { que es experimentadas } \\
\text { por los sujetos } \\
\text { (psicología de la emoción) }\end{array}$ & David Hume \\
\hline
\end{tabular}




\begin{tabular}{|c|c|c|}
\hline Enfoque & Descripción & Exponente (s) \\
\hline $\begin{array}{l}\frac{0}{0} \\
\frac{0}{00} \\
\frac{0}{0} \\
\frac{0}{40} \\
\frac{10}{1}\end{array}$ & $\begin{array}{l}\text { Establece que la } \\
\text { experiencia emocional, } \\
\text { parte de o desemboca } \\
\text { en una manifestación } \\
\text { corporal (existen } \\
\text { huellas de la emoción } \\
\text { en el cuerpo) }\end{array}$ & William James \\
\hline 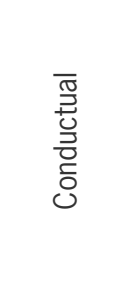 & $\begin{array}{l}\text { Reconoce las emociones } \\
\text { como causa de ciertas } \\
\text { conductas o respuesta a } \\
\text { determinados patrones } \\
\text { de comportamiento } \\
\text { (reacción de } \\
\text { causa-efecto) }\end{array}$ & $\begin{array}{c}\text { Charles Darwin } \\
\text { Dewey y Ryle }\end{array}$ \\
\hline 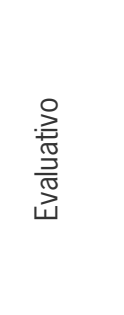 & $\begin{array}{l}\text { Exalta el carácter racional } \\
\text { de las emociones y las } \\
\text { relaciona con los juicios } \\
\text { de valor que realizan } \\
\text { los seres humanos, } \\
\text { tanto positivos, como } \\
\text { negativos (emociones } \\
\text { proclives y declives) }\end{array}$ & Jean Paul \\
\hline : & $\begin{array}{l}\text { Identifica las emociones } \\
\text { como respuestas } \\
\text { inteligentes ante } \\
\text { determinadas situaciones } \\
\text { y las vincula con las } \\
\text { creencias que conservan } \\
\text { los sujetos sobre el } \\
\text { mundo (reconoce } \\
\text { creencias y juicios } \\
\text { como parte constitutiva } \\
\text { de la emoción) }\end{array}$ & $\begin{array}{c}\text { Sartre } \\
\text { Franz } \\
\text { Brentano } \\
\text { Max Scheler }\end{array}$ \\
\hline
\end{tabular}

Elaboración propia, basada en los postulados de Calhoun y Solomon (1996)

Tal como lo expresan Calhoun y Solomon (1996), más allá de las similitudes y diferencias de los cinco enfoques, se trata de reconocer en las trayectorias teóricas del estudio de las emociones, la dicotomía entre aquellas vertientes que las sitúan como meras reacciones físicas, desprovistas de toda inteligencia y aquellas que defienden su carácter racional, e incluso, reconocen su carácter político.

\section{Emociones morales y políticas: miedo, amor e indignación}

Dentro del enfoque cognitivo-evaluativo, se encuentran los postulados de Martha Nussbaum (2006; $2008 ; 2014)$. Aunque la autora reconoce que todas las emociones conservan algún tipo de expresión corporal, defienden también que estas son experimentadas por cuerpos vivos, lo cual les confiere componentes cognitivos y las convierte en procesos mentales complejos que comprenden la vida privada y comunitaria. En otras palabras, las emociones “[...]no son impulsos afectivos sin sentido, sino respuestas inteligentes que están en sintonía tanto con los acontecimientos como con los valores y las metas importantes para la persona" (2008, p.52) Esto conlleva a vincularlas con el esquema de metas y fines de los sujetos, sus historias de vida, la idea que han construido de bienestar propio y colectivo, así como las formas de imaginación que orientan su experiencia de vida.

De esta forma, para Nussbaum $(2006 ; 2008)$ toda emoción comprende los siguientes atributos: 1 ) son acerca de algo o recaen sobre determinados objetos que le otorgan identidad; 2) conservar una intencionalidad; 3) contienen creencias; 4) comprenden juicios de valor, sobre las personas, objetos y situaciones; 5) se vinculan con la idea de eudaimonía o felicidad que conservan los sujetos y sus comunidades. Son precisamente estos atributos los que trasgreden el carácter irracional al que habían sido relegadas las emociones de manera histórica, permitiendo revelar su taxonomía, claro está, sin olvidar el carácter singular y diferencial en que son experimentadas por parte de los sujetos y sociedades.

El reconocimiento de estos atributos ha permitido a autores como Moisi (2009), Camps (2011) y la misma Nussbaum (2014) posicionar el papel de la sensibilidad en el escenario público y político. En palabras de Camps (2011), puesto que las emociones no son manifestaciones corporales, ni simples padecimientos, sino que se vinculan con aquello que los sujetos consideran valioso para sí mismos y sus comunidades, éstas paralizan o movilizan acciones que debilitan o fortalecen el tejido social. Ahora 
bien, ¿qué define el contenido de las emociones? Moisi (2009) y Nussbaum (2014) coinciden en señalar que son las normas y circunstancias sociales concretas las que permitan establecer geopolíticas emocionales o una organización emocional basada en las estructuras políticas de las sociedades; organización que puede dar cuenta de eventos de fortuna e infortunio.

Así, de acuerdo con Nussbaum (2014), la forma de pensar habitual conlleva a situar las emociones como peligrosas, atendiendo a los malos objetivos que estas han ayudado a sostener (nazismo, guerras, procesos de segregación). No obstante, la filósofa señala que, difícilmente se reconoce aquellas acciones positivas que estas han movilizado (procesos de resistencia, abolición de la esclavitud). Lo cierto es que las emociones deben ser comprendidas en sus matices, dimensiones y magnitudes, pues solo así es posible determinar su lugar en la promoción o mitigación de eventos de guerra y paz.

\section{Miedo y mal, gemelos siameses}

Para Bauman (2007), existe una emoción estrechamente vinculada al horror, por no decir inseparable, pues lo suscita, solventa, difunde y sostiene: “[...]Mal y miedo son gemelos siameses. Es imposible encontrarse con uno sin encontrarse al mismo tiempo con el otro" (p.75); su vínculo es tan estrecho, que ambos pueden referir una misma experiencia, siendo el mal aquello que proviene de fuentes externas al sujeto y el miedo lo que este experimenta o siente. Así, los seres humanos conciben como malo aquello que les causa temor y sienten miedo hacia aquello que conciben como malo: cuando se ensanchan los márgenes del mal, también lo hacen los del miedo.

Tanto Nussbaum (2006; 2008; 2013), como Bauman (2007), coinciden en señalar el carácter primitivo u originario del miedo, así como su universalidad, al ser experimentado por humanos y animales. Sin embargo, advierten los autores, a diferencia de las otras especies, los seres humanos conservan la consciencia de la muerte, lo que configura sus temores y los dota de sentidos y significados atendiendo a su historicidad y experiencia. Así, aunque en las primeras etapas de vida, se guarda un temor primario ante la vulnerabilidad y necesidad de supervivencia, con el curso de los años el miedo empieza a adquirir otras morfologías y valoraciones.

Estas morfologías del miedo, según Bauman (2007), pueden vincularse con la confrontación directa de situaciones ante las cuales los sujetos se han sentido amenazados, o con acontecimientos experimentados por otras personas, generalmente cercanas (miedos reciclados social y culturalmente). Asimismo, estas generalmente se relacionan con los posibles daños que pueden sufrir los sujetos en su condición física y en las propiedades de la persona, la duración y fiabilidad del orden social, las injusticias derivadas de las jerarquías sociales y, sin duda alguna, el ser víctima de hechos atroces.

Bauman (2007) muestra cómo miedo y mal para nuestros antepasados, solo eran posibles a través del pecado o quebrantamiento de una normal moral que conllevaba al castigo. Sin embargo, la experiencia de Auschwitz promovería en la humanidad la consciencia de la capacidad destructiva del hombre, su poder para idear, construir y propagar discursos y maquinarias de crueldad firmemente acompañas por la expansión del terror. Los sujetos evidenciaron que se hallaban enfrentados a males de origen humano, no menos crueles y difíciles de prever que los castigos religiosos o los desastres naturales.

Además de las características enunciadas, la obra de Bauman $(2007 ; 2015)$ y Nussbaum $(2008$; 2013), permite desglosar los siguientes atributos de esta emoción:

- Parte de un problema real. La imagen más concreta que adquiere el miedo es la vivencia de eventos y fenómenos cuya dimensión e impacto pueden recobrarse a través de los sentidos (observar, escuchar, palpar, oler, saborear). Esta emoción cobra cuerpo en situaciones posibles en el marco de la experiencia individual y colectiva de los sujetos (Nussbaum, 2013).

- Carácter disímil o confuso. El origen del miedo puede resultar desconocido, al punto de dar nombre a nuestra incertidumbre. Este estado de ambigüedad puede conducir a los 
sujetos a orientar sus percepciones negativas hacia determinados actores, objetos o acontecimientos, al considerarlos fuente de peligro, sin necesariamente ser el motor de lo vivenciado. Por ello, se dice que esta emoción se alimenta de la imagen amigo-enemigo, que en ocasiones simula no serlo (Bauman, 2007; 2015).

- Permeabilidad. El miedo conserva la capacidad de filtrarse en cualquier lugar y por cualquier medio. Por ello, esta emoción puede adquirir un estado de omnipresencia que resulta invasivo. Trasciende los espacios geográficos, cobra vida en los espacios más íntimos y públicos, adquiere rostro en personas, recorre las fibras del cuerpo y no existe un espacio en que no pueda hallarse (Bauman, 2007; 2015; Nussbaum, 2008; 2013).

- Alarma ante el peligro. Dentro de sus matices positivos, esta emoción se constituye en señal de alerta ante el peligro inminente, lo que permite la construcción y fortalecimiento de mecanismos de cuidado y protección que garanticen la supervivencia de los sujetos y las sociedades. En otras palabras, el miedo se convierte en un mecanismo valioso para garantizar la seguridad y bienestar (Nussbaum, 2013).

- Empoderamiento. La magnitud que adquiere el miedo no solo puede llegar a paralizar a los sujetos, también puede movilizar la acción y la capacidad de agenciamiento ante determinados eventos. De esta forma, experimentar miedo puede llevar al silenciamiento o huida, pero también a generar mecanismos individuales y colectivos para esclarecer y combatir los móviles de esta emoción (Nussbaum, 2013).

- Sensación de impotencia. El miedo siempre se acompaña de una sensación de impotencia (Bauman, 2007), pues la magnitud que adquiere el mal, así como su incomprensión, pueden trascender la capacidad humana para actuar. Los acontecimientos que trascienden el entendimiento de los sujetos generan respuestas de desubicación y respuestas no siempre acertadas para la precaución del terror, sin mencionar que existen eventos frente a los cuales no existen mecanismos de defensa.
Finalmente, es importante señalar que a pesar de los matices positivos y negativos de esta emoción para la vida en sociedad, el miedo, como otras emociones, conserva un carácter solipsista y estrecho, es decir, produce de manera inicial una atención centralizada en el mismo sujeto, haciendo difícil su ampliación hacia los círculos éticos cercanos y, aún más, hacia aquellos que consideramos lejanos: "[...]sufrimos por aquellos a quienes conocemos y no por aquellos a quienes no conocemos" (Nussbaum, 2013, p.83). Esto conlleva a los estudiosos de esta emoción a situar la necesidad de ampliar su estrechez bajo la premisa de la consecución del bienestar social.

\section{Indignación ante la injusticia}

En consonancia con Nussbaum (2006), el estudio de la indignación tiene su punto de partida y llegada en la teoría de Aristóteles. Para el filósofo griego, esta emoción tiene como base la idea que un mal o daño injusto ha sido cometido. Al contener las nociones de "mal" y "daño", es preciso acudir a aquello que los sujetos consideran malvado o dañino para su esquema de fines y metas o el de su comunidad. De esta forma, señala la autora, los motivos que movilizan esta emoción pueden ser falsos o no tener fundamento, así: 1) el daño no fue producido; 2) el daño fue producido, pero no precisamente por quien ha sido señalado como responsable; 3) el daño ocurrió y se conoce su gestor, pero el fin de la acción no contenía una intencionalidad destructiva; 4) la magnitud otorgada al daño cobra proporciones exageradas.

En adición a lo anterior, la filósofa señala el carácter estrecho que puede adquirir esta emoción, hasta el punto de llegar a experimentarse de forma solipsista, es decir, reconocer el daño que no ha sido infligido o que ha sido infligido a nuestros círculos éticos cercanos, pero no reconocemos el mal producido a otros congéneres que no resultan propiamente próximos. De esta forma, la indignación "puede estar mal orientada” (2006, p. 122) De allí que, en su dimensión política, esta emoción deba atender a las normas socialmente aceptadas, que rigen la vida con los otros. En palabras de Camps (2011), citando 
a Aristóteles, es precisamente la trasgresión de la norma lo que motiva su surgimiento.

Sumado a la preocupación por el esclarecimiento del causal y magnitud del daño, subyace a esta emoción la intención de reparación: "La indignación tiene una función constructiva; ella afirma 'estas personas han sufrido una injusticia y no deberían haberla padecido'. En sí misma, la indignación da incentivos para enmendar el mal" (2006, p. 127). De allí que sea concebida como constructiva para la justicia, pues conlleva al reconocimiento del mal, moviliza a las personas frente al mismo y promueve el desagravio.

Los planteamientos de Camps (2013) y Nussbaum (2006) en relación con esta emoción, permiten establecer los siguientes atributos:

- Ultraje-vejación. La indignación parte del reconocimiento de una injusticia que se vincula generalmente con el daño, maltrato, humillación u ofensa contra la dignidad de un sujeto o una comunidad. Lo que provoca la indignación es "[...] la falta de consideración, el no reconocimiento de lo que uno es, el ser tildado de inferior, el ser anulado o, sencillamente, no visto" (Camps, 2013, p. 154). Sin embargo, no se limita a la trasgresión de normas sociales, también se vincula con la vulneración de los derechos humanos y los principios morales más universales.

- Indiferencia. Uno de los móviles de la indignación es la ausencia de comprensión y corresponsabilidad con el daño que ha sido infligido. Por plurales y diversas que sean las sociedades, existen mínimos que permiten esclarecer aquellas actitudes que no merecen una reacción moral y las que convocan una empatía extendida, pues no solo se concibe como inmerecido el daño infligido, sino también se reconoce que este pudo ocurrirme a mí, de allí el vínculo de esta emoción con la compasión y el amor (Nussbaum, 2006; 2014).

- Resistencia -movilización. Como emoción política, la indignación no solo deviene al reconocimiento de un daño injusto, también convoca su reparación. Por ello “[...] se alimenta del compromiso por una realidad más justa y más armónica (...) expresa rechazo a una realidad que no deja de ser el escenario de crímenes, corrupciones y vejaciones constantes" (Camps, 2013, p. 172).

La indignación es concebida como una de las emociones políticas por excelencia (Nussbaum, $2006,2014)$, pues acaece en el reconocimiento de la común vulnerabilidad y moviliza la acción hacia objetivos comunes, considerados benéficos para los sujetos y las sociedades, claro está, cuando logra escapar de las barreras de la individualización.

\section{Metodología}

La investigación se realizó desde un enfoque cualitativo (Hoyos y Guillén, 1996; Sandoval, 1996; Strauss y Corbin, 2012), cuyo horizonte se basa en la comprensión de fenómenos sociales, a partir de la singularidad de la experiencia humana. Dicho enfoque, permitió hacer especial énfasis en el sustrato emocional que deviene a las voces de maestros y maestras, específicamente, el lugar que ocupan el miedo, la indignación y el amor en sus testimonios acerca del conflicto armado y los procesos de paz vividos en el departamento de Arauca. También, se asume un diseño narrativo, basado en los postulados de Ricoeur (1995). Este diseño permitió, a través de las tramas narrativas de los docentes, comprender los hechos, actores, espacios y tiempos que constituyen su vivir, obrar y sufrir en el marco de la guerra y el posacuerdo. En relación con los sujetos de enunciación, la investigación fue realizada con docentes de instituciones educativas públicas de tres centros poblados de Arauca: Panamá, Pueblo Nuevo y Filipinas.

\section{Estrategias de recolección de la información}

Para atender a la metodología propuesta, se implementan dos estrategias narrativas cuyo propósito es reconocer el papel que cumplen las emociones presentes en las voces de maestros y maestras del territorio de Arauca, específicamente el miedo y la indignación, en relación con las trayectorias de guerra y el actual proceso de posacuerdo vivido en el territorio: a) cartografía social con enfoque emocional; b) agendas territoriales de paz. 
Estrategias de sistematización y análisis de la información

Con el objeto de realizar la codificación, sistematización e interpretación de los hallazgos derivados del estudió, se utilizó parte de la Propuesta de Investigación Narrativa Hermenéutica PINH (Quintero, 2019). Basada en los postulados de Ricoeur, esta propuesta comprende cuatro momentos: 1) registro de codificación; 2) nivel textual; 3 ) nivel contextual; 4) nivel metatextual. No obstante, atendiendo a los propósitos que orientaron el presente estudio, se implementan los dos primeros momentos desde un enfoque emocional, así:

\section{Registro de codificación}

Se organiza y estructura la información en razón al objetivo propuesto en la investigación. Para ello, se realiza la transcripción de las narrativas derivadas del trabajo de campo y se procede a la asignación de códigos de identificación para las mismas. Este código corresponde al tipo y número de instrumentos, siendo cartografía social (Ст) o agendas territoriales de paz (AG)

\section{Nivel textual de preconcepción \\ de la trama narrativa.}

Una vez codificadas las narrativas, fueron categorizadas en los dos ejes de análisis establecidos en la investigación: miedo e indignación. De esta forma, para atender a los componentes de la trama, fueron identificadas a través de unas matrices analíticas:

- Acontecimientos vinculados al miedo y la indignación.

- Espacialidades vinculadas al miedo y la indignación.

- Tiempos del miedo y la indignación.

- Expresiones del miedo presentes en las narrativas.

- Expresiones de la indignación presentes en las narrativas.

\section{Interpretación y análisis}

Se realizó el proceso de interpretación y análisis de las narrativas partiendo de las categorías planteadas en la investigación. Si bien fue posible encontrar recurrencias y vacíos frente a las mismas, se buscó rescatar el carácter singular y diferencial de la experiencia vivida por los sujetos de enunciación.

\section{Resultados}

A continuación, se presentan los resultados encontrados en cada una de las categorías analíticas planteadas. Para ello, a partir de la sistematización y análisis de los hallazgos, se sitúan las expresiones que adquieren el miedo y la indignación en narrativas docentes, acerca de impacto del conflicto armado y los procesos de construcción de paz en el departamento de Arauca.

\section{Miedo paralizante en el marco}

del conflicto armado

En atención al análisis de los relatos es posible identificar tres expresiones del miedo presentes en las voces docentes; expresiones que se vinculan de manera estrecha con las trayectorias de guerra vividas en el departamento y permiten develar las formas que adquiere esta emoción para su difusión, persistencia y fortalecimiento.

\section{El departamento se debatía en un} mar de sangre, ese era el común ${ }^{1}$

La forma más concreta que adquiere el miedo en los testimonios de los docentes es la referencia a hechos o acontecimientos derivados del conflicto armado que difundieron el terror en el departamento de Arauca y trasgredieron las trayectorias de vida de los sujetos, así como la estabilidad del tejido social. Estos hechos son narrados en tres tiempos: calendario, histórico y humano.

En los relatos de maestros y maestras no cobra un lugar predominante el tiempo calendario,

1 La denominación de los acápites que estructuran los resultados, son códigos in vivo derivados del trabajo de campo realizado con los docentes en el territorio. 
pues son escasas las referencias a fechas y periodos precisos en que se sitúan los eventos atroces. Las alusiones existentes fijan la llegada de los docentes al departamento y el tiempo que han permanecido en el mismo "estoy en estas tierras araucanas desde el año 1996 y quién más yo para contarle a ustedes la experiencia que he vivido", "llevo 19 años acá y cuánto tiempo atrás se viene hablando de guerra" (CT6). Esta temporalidad, se constituye en argumento de propiedad para rememorar las trayectorias de guerra vividas y dar cuenta de su continuidad. Otra de las menciones, indica la llegada de la compañía petrolera al territorio en los años ochenta, así como las disputas de intereses generadas en torno a ella, a finales del siglo xx y principios del xxI. La afluencia del petróleo fortaleció el desarrollo en Arauca, pero también simbolizó más sangre.

Al deshojar el almanaque los docentes sitúan sus narrativas en un tiempo histórico pasado, a través del cual retratan la aparición de los primeros movimientos guerrilleros en el departamento - el ELN y posteriormente las FARC-; aparición que trajo consigo el advenimiento y consecuente propagación e instalación del terror en las comunidades. Así, se refieren los combates entre los grupos armados, las respuestas de las tropas del ejército, la ampliación de las maquinarias de la guerra, las disputas por la tierra y los cultivos ilícitos, entre otros eventos que afectaron de manera determinante los vínculos sociales y pusieron en riesgo la vida de los habitantes araucanos.

En lo que respecta al tiempo de la experiencia humana, son rememoradas las restricciones planteadas por las manecillas del reloj, esas que alertaban la llegada del peligro "[...]Si los individuos se quedaban después de las siete de la noche en Fortul, los degollaban, les quitaban la lengua, les quemaban la cabeza y los descuartizaban" (СT1). El lapso de la muerte intensifica el miedo con la llegada de la noche y advierte la nebulosidad del mal.

\section{Cerraba los ojos en esas tinieblas de guerra}

Otra de las expresiones que adquiere el miedo, es su carácter expansivo, traducido en la capacidad de recorrer y apropiarse de los espacios más abiertos, pero también de los más recónditos. La permeabilidad de esta emoción es situada por los docentes en dos tipos de espacios: geográficos (coordenadas), simbólicos (propios de la experiencia humana).

Las voces de los maestros y maestras refieren el miedo como una emoción que ha invadido el departamento en su totalidad, apropiándose con mayor fuerza de los municipios de Fortul, Tame, Saravena y Arauquita, referidos de manera reiterada como escenarios de constantes enfrentamientos por parte de los grupos armados al margen de la ley y como territorios cooptados por las maquinarias de la guerra "de aquí a Tame cuánta cantidad de carros bomba, cuántos cascabeles, cañones y toda esta cuestión" (AG1). La presencia sostenida de combates y residuos del mal, fortalecen la imagen de terror que recae sobre estas coordenadas.

Los recorridos del miedo continúan hacia espacios más concretos, tales como las carreteras, en las cuales los docentes manifiestan la posibilidad de encuentro con miembros del ejército o de grupos guerrilleros. También, se sitúan las fincas como epicentro de atentados atroces. Sin embargo, el temor conserva como punto de llegada permanente las instituciones educativas:

[...] en la finca del colegio han ocurrido hechos lamentables, como un campo minado, unas bombas, enfrentamientos (...) lo peor es que en alguna ocasión se estaban tomando fotos con unas granadas que encontraron, que son artefactos explosivos que no se habían detonado durante la guerra (AG6).

La guerra y el miedo adecúan cada rincón de las escuelas con sus mecanismos del horror y convierten lugares como la finca, en campos de combate.

Aunado a lo anterior, la aparición de expresiones como "podríamos salir a todo lado a la hora que quisiéramos" y "todos podríamos correr libremente", develan la capacidad que adquieren mal y miedo para irrumpir los escenarios de interacción comunitaria, al punto de restringir o poner limitaciones al tránsito en los mismos; escenarios antiguamente concebidos por la comunidad como puntos de encuentro e interacción. 
Finalmente, en relación con los espacios simbólicos, los docentes describen la forma en que la magnitud de la guerra lleva a las víctimas del conflicto a huir sin dirección determinada, pues todos los caminos parecen conducir a la muerte. De allí la aparición recurrente de las imágenes de la viuda, el huérfano y las familias desplazadas, como símbolo de incertidumbre y desolación: "[...]familias desplazadas en ese tiempo con sus maridos muertos, sus esposas viudas, niños solos, quienes tenían que irse sin un rumbo fijo, porque el miedo los hacía salir sin saber para dónde, ni a hacer qué" (СT2). Al permear todos los caminos, el miedo cristaliza las tinieblas de la guerra.

\section{El departamento estaba convulsionado,} no había para dónde mirar

La tercera expresión del miedo es la alarma ante el peligro posible o inminente. Esta se vincula con espacios, objetos y rostros que resultan amenazantes para el bienestar de los sujetos y sus comunidades en el marco de la atrocidad, razón por la cual confluyen en la parálisis de la acción o la construcción de estrategias de protección.

En este sentido, el conocimiento de lo que ocurría en Fortul pasadas las siete de la noche a quienes transitaban por el municipio, así como el desconocimiento del incalculable número de artefactos explosivos que podían estar presentes camino a Tame, se constituyen en advertencia ante un posible daño. A esto se suma el reconocimiento de las nuevas dinámicas que adquiere la atrocidad en el territorio, tales como el paso de los enfrentamientos directos, al uso de carros, motos y bicicletas bombas y la instalación de minas antipersona en lugares estratégicos, lo que aumenta las señales de alarma para los habitantes del departamento, quienes conscientes del peligro que representa recorrer determinados trayectos, los evitan o realizan con precaución. Guerra y miedo imponen sus normas, custodiando uno a uno los pasos de sus víctimas.

Asimismo, la cooptación de la escuela como tablado para la guerra se vuelve señal de alarma para los docentes en dos sentidos. De una parte, aparece el riesgo de ejercer la profesión ante la amenaza de las armas, de otra, surge el temor por la seguridad de niños, niñas y jóvenes, pues la escuela había dejado de ser aquel espacio seguro y protector en que era posible pensar otras formas de vida diferentes. Junto a las batallas armadas emprendidas en estos claustros de conocimiento, se refiere la llegada de miembros de los grupos armados al margen de la ley, quienes emprendían conversación con los estudiantes.

Otras señales de alarma cobran forma en la figura de las guerrillas, el ejército y los campesinos. Los primeros, alertaban la proximidad de un enfrentamiento o la ejecución de represalias; los segundos, representaban la posibilidad de combatir el mal, o reproducirlo a través de ejecuciones sobre la población civil, especialmente los campesinos, quienes eran asociados a los grupos armados al margen de la ley; los terceros, simbolizaban temor, pues su vínculo con el campo y la tierra, se constituían en argumentos para relacionarlos con los grupos guerrilleros. Sin embargo, la presencia constante de estos tres tipos de actores en el territorio hacía de Arauca un escenario en el que no había hacia dónde mirar.

\section{Indignación ante una guerra que}

se resiste a desaparecer

La indignación que subyace a las narrativas de los docentes se sitúa de manera imperante en la continuidad de la guerra y el incumplimiento de los acuerdos de paz en el departamento. Al respecto, es posible referir tres expresiones que adquiere esta emoción:

\section{Y aquí estamos, todavía viviendo la guerra}

La primera expresión de la indignación se vincula con la percepción de acciones injustas, generalmente vinculadas con la presencia de formas de menosprecio, tales como vejaciones y ultrajes. Así, los maestros y maestras refieren el surgimiento de esta emoción frente a las largas trayectorias de guerra que ha debido padecer la comunidad y que, aún hoy, con la firma de los Acuerdos de Paz, continúa sufriendo. De allí que esta emoción también sea equiparada con el incumplimiento de estos acuerdos. 
Al respecto, los docentes señalan como ofensivo el discurso estatal, según el cual el departamento ha transitado de la guerra, al proceso de posacuerdo: "lo que usted mira aquí es intención de guerra” (CT1), “[....] por todo lado hemos seguido viendo muerte, familias desplazadas, viudas, conflicto, secuestro y la cosa continúa igual" (Ст3). Esto conlleva al señalamiento imponente y recurrente de la permanencia de la atrocidad en el territorio y al bosquejo de los acuerdos como símbolo de quebrantamiento de las promesas realizadas: restitución de tierras, fortalecimiento educativo, reestructuración de vías, pero especialmente, procesos de reparación y reconciliación.

En adición a lo anterior, los maestros y maestras expresan su descontento con el carácter selectivo que han tenido los beneficios de los acuerdos, los cuales han privilegiado a determinados actores, dejando a los más afectados en la misma situación "[...] ellos se salieron, se fueron a estudiar muy orondos, el que se pudo acomodar se acomodó y el resto lleve del bulto (...) el pobre quedó hundido, el que estaba dentro de su guerra, quedó en su guerra" (Ст1). También, han referido la falta de esclarecimiento por parte del gobierno, de los impactos de la guerra y las necesidades, así como de las capacidades territoriales para la construcción de paz, lo cual se ve reflejado en la reglamentación de una Cátedra de Paz generalizada.

Otra de las fuentes que moviliza la indignación, es la ausencia de reconocimiento demandada por los docentes, de su condición de víctimas del conflicto armado. Junto a este punto, se presenta el descontento generado frente al hecho que estudiosos de la violencia hablen y debatan sobre la situación del departamento, cuando no han vivido sus efectos, ni se han preocupado por acercarse de manera directa esta realidad.

$\mathrm{Al}$ respecto, señalan que quienes han vivido de manera directa los impactos de la guerra, no han sido precisamente quienes han contado lo ocurrido en el país, pues a pesar de ser uno de los actores más afectados, los maestros no han sido escuchados. De allí, la reiteración de sentencias como: "nosotros como docentes podemos contar nuestra realidad", "quién más que yo para contarle a ustedes la expe- riencia que he vivido", "eso es lo que nosotros vimos, vivimos y visualizamos" y "con autoridad puedo hablar de eso", las cuales exigen la escucha de la experiencia docente en el marco de una guerra que marcó su trayectoria.

\section{Nosotros como docentes podemos} contar nuestra realidad

Otro de los móviles de la indignación es la indiferencia. Al respecto, las voces de los docentes hacen especial énfasis en la ausencia de acciones por parte del Estado y de las familias, ante la inmersión sustantiva de niños, niñas y jóvenes en los grupos guerrilleros "[....] en años anteriores, a cantidad de jóvenes los perdíamos, porque ellos ingresaban allá y los papás jum, no se les daba mucho, porque eso era lo que vivíamos acá" (ст6). Esta suerte de olvido aumentaba la desesperanza e impotencia de los maestros, quienes eran testigos de la falta de condiciones de vida digna para niños, niñas y jóvenes en el territorio.

La indignación, también cobra cuerpo en la pérdida del plebiscito por la Paz realizado por el gobierno en el mes de octubre de 2016. Los docentes consideran humillante las cifras de abstinencia reportadas en las votaciones, pero especialmente, aquellos casos en que el No fue la opción de voto predilecta en territorios que "no han experimentado la guerra en carne propia” (AG3). Aquí, aparece nuevamente la advertencia frente a la ausencia de comprensión de los impactos y efectos que ha traído la guerra en el departamento.

Finalmente, los educadores expresan su indignación en relación con la ausencia de un interés colectivo por hacer del posacuerdo algo posible. Aunque se señala la preocupación de las instituciones educativas y del gremio por promover la permanencia de niños, niñas y jóvenes en las escuelas mediante la reivindicación de esta última como escenario de apertura hacia otras realidades y oportunidades de vida, diferentes a las ofertadas por la guerra, se hace mención reiterada de la necesidad de apoyo por parte de los otros actores de la comunidad, para alcanzar dicho fin. 
No es una paz, que diga uno está completa, pero todos estamos luchando para que sea así

La tercera expresión que adquiere la indignación son los procesos de resistencia y movilización. Tras los diálogos de paz emprendidos por el expresidente Belisario Betancourt, los docentes refieren la conformación de los primeros sindicatos en el departamento. Solventados en el agotamiento producido por las largas trayectorias de guerra, estos guardaban como propósito la exigencia del cese a la violencia y la construcción de escenarios de conversación de paz dentro del territorio.

Otra de las circunstancias que movilizó procesos de resistencia dentro del departamento, fueron los constantes procesos de maltrato y humillación sufridos por la población, vinculados con estigmas y estereotipos que recaían sobre la historicidad de la guerra en el mismo. Estos procesos cobraron tal fuerza y magnitud, que ser araucano llegó a ser equiparado con ser guerrillero "[...] si su cédula es de Arauca le tenían que hacer mil preguntas”, “[...] cuántos no dejaban en los retenes por tener cédula de Arauca y los dejaban porque posiblemente era guerrillero" (AG2). Estas prácticas de menosprecio, condujeron a la movilización de diferentes familias a realizar el registro de sus hijos en otras ciudades, como práctica de cuidado y resistencia ante los ultrajes reiterados.

No obstante, la práctica de resistencia señalada por los docentes como la más valerosa de todas es la educación. Para los maestros y maestras, su mayor aporte a la construcción de paz en el territorio ha sido la permanencia y lucha dentro de las instituciones educativas. A pesar de la cooptación de estos escenarios por parte de los actores armados, las escuelas y la educación en general, han aparecido como posibilidad de arrebatarle la infancia y la juventud a la guerra "[...] han venido a las puertas a esperar a los muchachos y decirles yo soy de las FARC por qué no se viene con nosotros, pero ahí está la escuela como una alternativa" (AG1); resistencia que cobra vida en las narrativas a través del amor.
Los docentes señalan la necesidad del amor como emoción que conduce a los sujetos a un "desarmarse espiritualmente" y "desarmarse frente a los demás", promoviendo nuevos y fortalecidos vínculos. Esta emoción, vinculada por los maestros a los procesos de resistencia, como respuesta a la indignación, permite olvidar el odio, el rencor y la violencia, cambiando el "chip de la guerra" por nuevas oportunidades de vida cuyo sustrato se encuentra en la educación de un "nosotros" capaz de generar transformaciones de una paz que no está completa, pero en la que todos luchan para que sea así.

\section{Conclusiones}

Las narrativas de maestros y maestras permitieron identificar desde una perspectiva singular y diferencial, las expresiones que adquieren el miedo y la indignación en el marco de la experiencia del conflicto armado y el proceso de posacuerdo en el territorio de Arauca; expresiones que paralizan y/o movilizan su accionar social y pedagógico.

En lo que respecta al miedo, los docentes sitúan diversos acontecimientos atroces que promovieron el terror en Arauca, entre ellos, la llegada de los grupos armados al margen de la ley, el arribo de la compañía petrolera y las disputas por la tierra. Sin embargo, es preciso señalar la ausencia de referencias cronológicas dentro de las trayectorias de guerra y paz presentadas. Junto a los acontecimientos enunciados, es posible evidenciar la forma en que esta emoción se expande a lo largo y ancho del territorio. Sus trayectorias comprenden una mirada global del departamento y se van aproximando de manera cada vez más incisiva, a determinados espacios en los que discurre la experiencia comunitaria, tales como las calles, fincas e instituciones educativas, estas últimas, escenarios altamente afectados por la guerra.

Otro de los puntos a resaltar, es la imagen de la viuda y el huérfano como símbolos del (no) lugar de las víctimas en medio de la guerra, es decir, de un miedo que no acaba en la vivencia de la atrocidad, sino que muta en el trasegar de un camino indefinido, sin directrices ni destino más que el deseo 
de huir de lo vivido, recobrando tras cada paso las huellas del horror. Así, tal como lo señala Bauman (2007), al ensancharse los márgenes del mal, se amplían también los del miedo.

En relación con los matices que adquiere esta emoción, es preciso señalar la prevalencia de su capacidad para paralizar a los sujetos, antes que empoderarlos. Aunque el miedo permite situar en las narrativas mecanismos de defensa y protección ante los peligros y amenazas de la guerra, no resultan visibles acciones que resistieran a la misma, al menos antes de los diálogos de paz. Contrario a ello, la presencia de expresiones como "ese era el común", "así se vivía aquí" y “así era”, develan la desesperanza que miedo y mal infundieron en el departamento, paralizando el accionar de la comunidad.

En lo que respecta a la indignación, aparece la demanda de escucha y la exigencia de reconocimiento como víctimas del conflicto armado por parte de los docentes; demanda y reconocimiento que ha sido señalado por algunos estudiosos del tema. Aunado a ello, se sitúa la inconformidad de los maestros en relación con la propagación de trabajos y estudios vinculados con los procesos de guerra y paz vividos en el territorio, los cuales no comprenden un acercamiento real a las experiencias acaecidas, ni tienen en cuenta sus voces como actores clave para comprender lo ocurrido.

Es importante exaltar la forma en que permanecer en el territorio y continuar con el ejercicio docente, aun en medio de la condición amenazante derivada de la guerra, es reconocido por maestros y maestras como el mayor acto de resistencia y aporte a la construcción de paz en el departamento. Aunque el ruido de las armas no haya cesado, la labor de los maestros ha permitido que niños, niñas y jóvenes, lo conviertan en el eco de una historia que espera convertirse en nunca más.

Finalmente, contrario a los señalamientos de Nussbaum $(2006,2013)$, en relación con el carácter solipsista del miedo y la indignación, dichas emociones son referidas con amplitud, atendiendo a la necesidad de construir mecanismos de protección $\mathrm{y}$ resistencia que garanticen el bienestar colectivo, de allí que las narrativas den origen a los vestigios del amor como emoción política que permite pensar la construcción de paz desde un nosotros. En otras palabras, esta emoción implica reconocer la polifonía y actuar desde la colectividad, para movilizar la historia hacia otro rumbo.

\section{Referencias}

Bauman, Z. (2007). Miedo líquido. La sociedad contemporánea y sus temores.Barcelona: Paidós Estado y sociedad.

Bauman, Z. (2015). Ceguera moral. La pérdida de sensibilidad en la modernidad líquida. Barcelona: Paidós Estado y sociedad.

Bello, M (2005) Bojayá: la culpa de las víctimas y de los victimarios. Desde el jardín de Freud, 5, 242-255. Bogotá D.C. Universidad Nacional de Colombia.

Calhoun, C. y Salomon, R. (1996). ¿Qué es una emoción? Ciudad de México: Fondo de Cultura Económica.

Camps, V. (2011). El gobierno de las emociones. Barcelona: Editorial Herder.

Carrera, E. (2015). El miedo en la historia: testimonios de la Gran Guerra. Rubrica Contemporánea, 4(7), 47-66.

Cárdenas, M., Ascorra, P., San Martin, M. Rodríguez, M., Páez, D. (2013). Emociones como predictores del perdón en el contexto de la violación a los derechos humanos en Chile. Revista Psicoperspectivas: individuo y sociedad. 12, 1 .

Departamento Nacional de Planeación. (2015). Índice de Incidencia del Conflicto Armado. Recuperado de https://colaboracion.dnp.gov.co/CDT/Poltica $\% 20$ de\%20Vctimas/Construcci\%C3\%B3n\%20de\%20 Paz/Documento\%20\%C3\%ADndice\%20de\%20 incidencia\%20del\%20conflicto\%20armado.pdf

Fondo Colombia en Paz (2015). Documento Conpes 3850. Consejo Nacional de política económica y social. Recuperado de https://colaboracion.dnp.gov. co/CDT/Conpes/Econ\%C3\%B3micos/3850.pdf

Franco, A. (2014). Significado del impacto de la guerra en la memoria emocional de un soldado que perteneció a las fuerzas armadas de Colombia. (Tesis de grado). Universidad de San Buenaventura.

Lizarralde, M. (2003). Maestros en zonas de conflicto. Revista Latinoamericana de Ciencias Sociales, Niñez y Juventud, 1(2), 79-114. 
Lizarralde, M. (2013). Ambientes educativos y territorios del miedo en medio del conflicto armado: estudio sobre escuelas del Bajo y Medio Putumayo. Revista Colombiana de Educación, 62, 21-30.

Guzmán Moreno; K., Fernández Cediel, M. C. y Villalba Herrera, L. Y. (2016). Emociones en niños, niñas y adolescentes desde la experiencia del desplazamiento y la vinculación a los grupos armados en Colombia. Panorama, 10(19), 124-149.

Moisi, D. (2009). La geopolítica de las emociones. Cómo las culturas del miedo, la humillación y la esperanza están reconfigurando el mundo. Bogotá: Grupo Editorial Norma.

Nussbaum, M. (2006). El ocultamiento de lo humano. Repugnancia, vergüenza y ley. Buenos Aires: Editorial Katz conocimiento.

Nussbaum, M. (2008). Paisajes del pensamiento: la inteligencia de las emociones. Barcelona: Grupo planeta.

Nussbaum, M. (2013). La nueva intolerancia religiosa. Cómo superar la política del miedo en una época de inseguridad. Barcelona: Paidós Estado y Sociedad.

Nussbaum, M. (2014). Emociones políticas ¿Por qué el amor es importante para la Justicia? Barcelona: Equipo Editorial.

Quintero Mejía, M. (2019). Pedagogía para la paz territorial. Bogotá: Universidad Distrital Francisco José de Caldas (en proceso de publicación).

Quintero Mejía, M. (2018). Usos de las narrativas, epistemologías y metodologías. Aportes para la investigación. Bogotá: Editorial Universidad Distrital Francisco José de Caldas

Quintero Mejía, M. (2017). Geopolítica de las emociones en tramas narrativas de la ciudadanía: altericidio. En Cátedra doctoral Educación, política y subjetividad (pp. 41-60). Universidad Pedagógica Nacional.
Quintero Mejía, M. (2015). Pedagogía de las emociones para la paz. Bogotá: IDEP

Quintero Mejía, M. (2009). Las narrativas del mal: investigación de las simbólicas en el desplazamiento forzado. Actualidades Pedagógicas, (54), 69-77. https:// doi.org/10.19052/ap.951

Quintero Mejía, M. (2009) Enseñanza de la historia del conflicto armado en Colombia: fundamentos para la construcción de propuestas para su enseñanza en el ámbito universitario. Revista Latinoamericana de Estudios Educativos, 5, 205-230.

Ricoeur, P. (1995). Tiempo y Narración I. Configuración del tiempo en el relato histórico. México: Siglo Veintiuno Editores

Rodríguez, M. (2012). La cultura del miedo en un escenario de guerra. En Estados Unidos y América Latina en la nueva dinámica hemisférica, (pp.119-136). Ciudad: CLACSO

Romanos, E. (2011). Emociones, identidad y represión: el activismo anarquista durante el franquismo. Reis, 134, abril-junio, 87-106.

Strauss, A. y Corbin, J. (2012). Bases de la investigación cualitativa. Técnicas y procedimientos para desarrollar la teoría fundamentada. Medellín: Universidad de Antioquia.

Toro, P. (2015). Tiempos tristes: notas sobre movimiento estudiantil, comunidad y emociones en la Universidad de Chile ante la dictadura de Pinochet (1974-1986). Espacio, Tiempo y Educación, 2(2), 107-124.

Villa, M. (2006). Desplazamiento forzado en Colombia. El miedo: un eje transversal del éxodo y de la lucha por la ciudadanía. Controversia, 187, 12-45. 